\title{
BRAF NP_004324.2:p.K601E
}

National Cancer Institute

\section{Source}

National Cancer Institute. BRAFNP 004324.2:p.K601E. NCI Thesaurus. Code C146881.

A change in the amino acid residue at position 601 in the serine/threonine protein kinase

B-raf protein where lysine has been replaced by glutamic acid. 